\title{
Morphometric model and laboratory analysis of intracohort cannibalism in giant grouper Epinephelus lanceolatus fry
}

\author{
Jinn-Rong HSEU, ${ }^{1 *}$ Pung-Pung HWANG ${ }^{2,3}$ AND Yun-Yuan TING ${ }^{1}$ \\ ${ }^{1}$ Mariculture Research Center, Fisheries Research Institute, Chiku, Tainan 724, ${ }^{2}$ Institute of Zoology, \\ Academia Sinica, Taipei 115 and ${ }^{3}$ Institute of Fisheries Science, National Taiwan University, \\ Taipei 106, Taiwan
}

\begin{abstract}
During larviculture of giant grouper, Epinephelus lanceolatus, intracohort cannibalism usually results in mass mortality. Thus, in the present study, we attempted to develop a cannibalprey length relationship from morphometric measurements for giant grouper fry and to verify it with pairwise predation experiments. Based on measurements of morphometric characteristics (i.e. mouth width, body depth, and total length), a model of prey length $(\mathrm{mm})$ to cannibal length was constructed: $\mathrm{TL}_{\text {prey }}=0.83 \mathrm{TL}_{\text {cannibal }}-2.48$. According to the equation, approximately $30 \%$ is a threshold in total length differences to use for grading giant grouper fry. The threshold was supported by our pairwise experiments using 136 pairs; we found that 33 out of 36 cannibalism incidents occurred only when the prey was of equal or smaller size than that predicted by the equation. In aquaculture practice of this species, we thus suggest that when the length of larger fry exceeded that of smaller fry by more than $30 \%$, the potential cannibals should be removed.
\end{abstract}

KEY WORDS: cannibalism, Epinephelus lanceolatus, morphometric model.

\section{INTRODUCTION}

Cannibalism, or intraspecific predation, is the process in which an individual kills and eats a member of its own species. ${ }^{1}$ It was originally regarded as an artifact of laboratory systems or to occur in cases under severe stress. But, now, many authors think that the behavior is a normal phenomenon in natural populations and it has been widely observed in the animal kingdom, from protozoans to primates. For a cannibal, cannibalism has its benefits and costs. ${ }^{1,2}$ The most obvious benefit is that a cannibal can gain food (i.e. consumption of prey). However, during cannibalism, a cannibal may run the risk of becoming prey to its potential victim and of infection from parasites, viruses and other diseases. $^{3}$

Cannibalistic behavior is far more common in fishes than in terrestrial vertebrates. ${ }^{4}$ The occurrence of cannibalism has been identified in at least 36 families of fish. ${ }^{3}$ In fact, Dominey and Blumer, ${ }^{4}$ considered that cannibalism occurs in virtually all natural populations of fish. According to the

\footnotetext{
${ }^{*}$ Corresponding author: Tel: 886-6-7880461 ext. 229. Fax: 886-6-7881597. Email: jrhseutfri@pchome.com.tw Received 12 September 2003. Accepted 2 February 2004.
}

genetic relationship between cannibal and prey, the behavior can be classified into three types: filial cannibalism (a parent eats its own offspring), sibling cannibalism (fratricide) and heterocannibalism (non-kin cannibalism). ${ }^{3,4}$ Compared to those in natural populations, cultured fishes have little or no chance of escaping predation via habitat segregation or migration. ${ }^{5}$ Additionally, larval and juvenile fishes have higher growth capacities than adults. Thus, young generally consume large ratios relative to their body size and are prone to growth depensation (divergence in size among fish of the same age group), which may facilitate and enhance cannibalism. $^{5,6}$

Groupers of the genus Epinephelus are economically important cultured finfish in East Asian regions. In Taiwan, at least four species are often propagated: malabar grouper (E. malabaricus), orange-spotted grouper (E. coioides), tiger grouper (E. fuscoguttatus) and giant grouper (E. lanceolatus). Giant grouper is one of the two largest species of groupers in the world. ${ }^{7}$ Due to its fast growth and high price, ${ }^{8}$ giant grouper currently is regarded as a favorite species for marine culture in Taiwan. However, massive seed production is still encountering many difficulties and survival rates are generally low. ${ }^{9}$ Generally, difficulties in larviculture are usually due to unstable egg quality, insufficient 
food availability and nutrients, poor environmental quality, diseases, and cannibalism. ${ }^{9}$

In grouper, intracohort cannibalism is usually observed at the late larval and juvenile stages. ${ }^{9-14}$ Body size disparity is thought to be the major cause of cannibalism and there are some factors, such as feeding grouper inadequately, that will intensify their differential growth. ${ }^{9-13}$ Therefore, routine size grading is not only an important but also a commonly used method to mitigate cannibalism in grouper larviculture. Also, this method usually results in better survival rates. ${ }^{9,10,13,15}$ Herein, we attempted to develop a cannibal-prey length relationship from morphometric measurements for giant grouper fry and to verify it with pairwise experiments. The aim of the present study was to determine a threshold in size disparity beyond which cannibalism could occur so that potential cannibals and prey can be separated in advance.

\section{MATERIALS AND METHODS}

About 800 giant grouper fry were purchased from a private hatchery in Tainan County, Taiwan. They were cultured in 50-L glass aquaria and outdoor concrete ponds. The minimum length of the fry was about $19 \mathrm{~mm}$. During rearing, frozen adult Artemia and minced fish meat were offered to the grouper fry as feed. To prevent serious cannibalism, the grouper fry were routinely graded into different sizes and were placed into different cage nets. Water temperature and salinity during the experiment were $25-31^{\circ} \mathrm{C}$ and $30-35$ p.p.t., respectively.

The first experiment was to measure the morphometric parameters and then to construct an equation between the total lengths (TL) of cannibal and prey. We found that grouper cannibals generally engulf whole prey horizontally (i.e. type II cannibalism) ${ }^{14}$ This implies that a grouper cannibal can swallow a prey only when the cannibal's mouth width (MW) is greater than or equal to the prey's body depth (BD). Based on these observations, we first developed two linear regression equations of BD versus TL and MW versus TL, and then combined the two equations to create a theoretical equation relating $\mathrm{TL}_{\text {prey }}$ and $\mathrm{TL}_{\text {cannibal. }}$. Periodic sampling was carried out every $4-5$ days. In total, 186 groupers, ranging in TL from about 19$71 \mathrm{~mm}$, were used for measurements of TL, MW and BD. In some cases, certain specimens might have repeatedly been sampled at different body sizes. Fish were anesthetized with $400 \mu \mathrm{L} / \mathrm{L} 2$ phenoxyethanol before measurement. The measurement method of morphometric parameters was the same as that used in the orange-spot- ted grouper. ${ }^{14}$ With a dial caliper, TL was measured to the nearest $0.05 \mathrm{~mm}$ as the distance from the tip of the snout to the end of the tail; MW was measured as the widest distance when the mouth formed an ' $\mathrm{O}$ ' shape; and $\mathrm{BD}$ was measured as the distance from the anterior insertion of the dorsal fin to the anterior insertion of the ventral fin.

Pairwise experiments were made to test the reliability of the above equation. In the experiment, 136 pairs of cannibal-prey with varying size ratios were used. We attempted to include a wide range of sizes and ratios. Before the experiment, fish from large (cannibal) - and small (prey)-size groups were chosen and separated into individual nets. Both sizes of fish were starved for 1 day. When the experiment started, the two sizes of fish were anesthetized with $400 \mu \mathrm{L} / \mathrm{L} 2$-phenoxyethanol and their TL were carefully measured to the nearest $0.05 \mathrm{~mm}$. Each pair of fish was cocultured in a glass aquarium $(30 \times 15 \times 28 \mathrm{~cm})$ containing $10 \mathrm{~L}$ seawater. After $24 \mathrm{~h}$, we recorded the predation result of each trial.

\section{RESULTS}

The linear regression equations (Fig. 1) of giant grouper BD and MW on TL are:

$$
\begin{gathered}
\mathrm{BD}=0.29 \mathrm{TL}-0.35(r=0.99) \\
\mathrm{MW}=0.24 \mathrm{TL}-1.07(r=0.99)
\end{gathered}
$$

The largest prey should have a BD equal to the MW of the cannibal, so we combined equations 1 and 2 to construct a theoretical equation relating $\mathrm{TL}_{\text {prey }}$ and $\mathrm{TL}_{\text {cannibal: }}$ :

$$
\mathrm{TL}_{\text {prey }}=0.83 \mathrm{TL}_{\text {cannibal }}-2.48
$$

Equation 3 shows that the theoretical minimum $\mathrm{TL}_{\text {cannibal }}$ is approximately $1.35-1.26$ times $\mathrm{TL}_{\text {prey }}$ when the value of $\mathrm{TL}_{\text {prey }}$ is from 20 to $50 \mathrm{~mm}$.

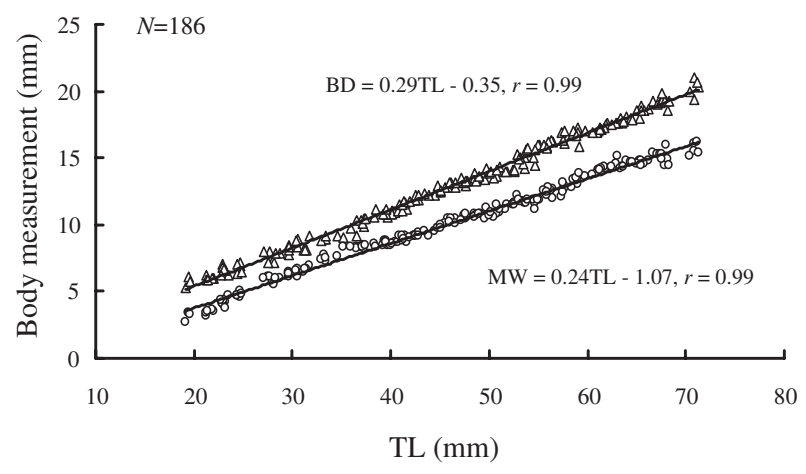

Fig. 1 Linear regressions of mouth width (MW) and body depth (BD) on total length (TL) in giant grouper Epinephelus lanceolatus. 


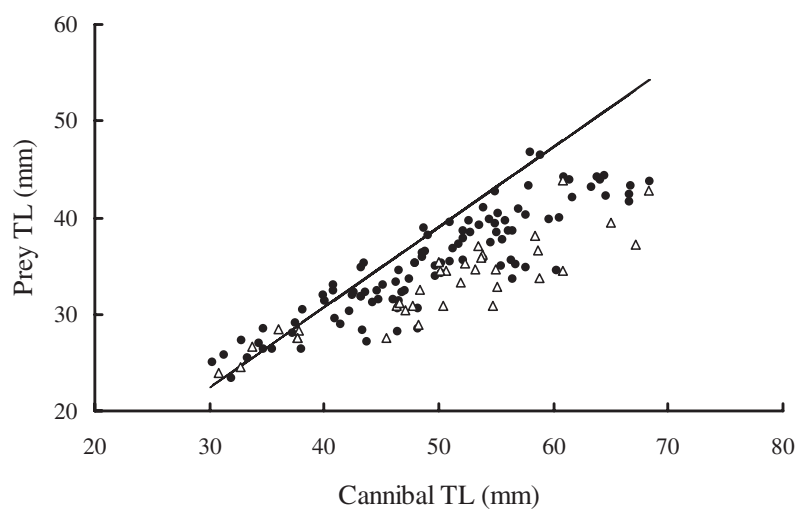

Fig. 2 Results of pairwise interactions in giant grouper fry $(N=136)$. The solid line represents the predicted maximum prey size based on the equation: $\mathrm{TL}_{\mathrm{PR}}=0.83 \mathrm{TL}_{\mathrm{CA}}-2.48$. $(\triangle)$ when cannibalism occurred among pairwise interactions; $(\bullet)$ when cannibalism did not occur among pairwise interactions.

The theoretical minimum $\mathrm{TL}_{\text {cannibal }}$ calculated from equation 3 was compared with the observed data. Out of 136 pairs of fry set up in the experimental aquaria, cannibalism occurred 36 times (Fig. 2). Most of the cannibalism occurred when the prey was of equal or smaller size than that predicted by the above equation. However, there were three cases that illustrated that certain cannibals can ingest prey with a larger TL than that expected by our morphometric measurements. The situations occurred with cannibals of smaller sizes, less than $40 \mathrm{~mm}$, but the ratios of $\mathrm{TL}_{\text {cannibal }} / \mathrm{TL}_{\text {prey }}$, which ranged from 1.26 to 1.28 , did not vary far from the expected value of approximately 1.32. No similar situation was found in cannibals over $40 \mathrm{~mm}$.

\section{DISCUSSION}

In the orange-spotted grouper, cannibalism was observed to begin in fry with a TL larger than $13 \mathrm{~mm} \cdot{ }^{11,14,16}$ Before that stage, lengths of grouper are generally too similar to allow intracohort cannibalism. ${ }^{14}$ Additionally, the feeding elements (e.g. the teeth) of grouper are incompletely developed. ${ }^{16}$ Grouper cannibals thus cannot effectively grasp their prey. We think that cannibalism in giant grouper begins before they reach $19 \mathrm{~mm}$ in TL. Thus, our model does not cover the entire length range at which cannibalism occurs. However, serious cannibalism in many grouper species is found at TL larger than $25 \mathrm{~mm}$, when the elongated dorsal and pelvic spines shorten and do not interfere with predation by cannibals, ${ }^{11,17}$ and does not stop until fish reach lengths of $50-60 \mathrm{~mm} \cdot{ }^{10,11,14}$ Additionally, we often observed the occurrence of cannibalism in the aquaria and concrete ponds during the sampling period. Thus, we think that the regression model can still be used to accurately predict and prevent the occurrence of cannibalism in giant grouper.

Many linear regression models have been developed to analyze or predict the occurrence of fish cannibalism. Some of the models were derived from direct measurements of TL in observed cannibals and prey. ${ }^{18-21}$ However, the cannibalism of many fishes such as grouper belongs to type II cannibalism. This type of cannibalism can succeed only when a cannibal's mouth gape or width is equal to or exceeds the prey's depth or width. ${ }^{5}$ Therefore, some ichthyologists have measured these morphometric parameters and indirectly estimated the minimum cannibal size from the relationship between mouth gape (or width) and depth (or width) relative to the TL of fish. ${ }^{14,20,22-24}$ The indirect models sometimes may somewhat over- or underestimate minimum total lengths of cannibals. However, they are much more easily obtained than directly measured models and have often been proven useful in predicting cannibalism between fish with known size distributions.

In the present study, except for three cases, we found that cannibalism occurred only when the prey had equal or smaller sizes than that predicted by the equation. However, although the three cases that showed that cannibals were able to ingest prey with larger TL than that calculated by our morphometric measurements, the ratios of $\mathrm{TL}_{\text {cannibal }} / \mathrm{TL}_{\text {prey }}$ did not vary far from the expected values. The cannibals in the three cases were less than $40 \mathrm{~mm}$. Grover found that pelagic early juvenile Nassau grouper E. striatus $(20.2-27.8 \mathrm{~mm})$, were able to protrude their upper jaw, which resulted in buccal gape expansion, in order to ingest very large prey, such as fish larvae. ${ }^{25}$ This could be an explanation for why the smaller cannibals were able to engulf the prey with a slightly larger size than that predicted by the equation. In larger cannibals $(>40 \mathrm{~mm})$, the minimum $\mathrm{TL}_{\text {cannibal }} / \mathrm{TL}_{\text {prey }}$ ratio with successful cannibalism was 1.39. Therefore, we still suggest that the threshold for TL difference, 26-35\%, obtained from equation 3 is reasonable and is safe to use in grading giant grouper fry.

Size disparity for which cannibalism occurs varies with different fish species. ${ }^{5,15,26}$ When comparing our equation with the regression models of various marine fishes (listed in Table 1), we found that the minimum TL of giant grouper cannibals was much smaller than those of many marine fishes when their prey had the same TL. For exam- 
Table 1 Relationship between total lengths of cannibal and prey among selected marine fishes

\begin{tabular}{lccc}
\hline Species & Size interval $(\mathrm{mm})$ & Equation & Reference \\
\hline Engraulis capensis & $\approx 3-35$ & $\mathrm{TL}_{\mathrm{PR}}=0.58 \mathrm{TL}_{\mathrm{CA}}-2.90(\mathrm{M})$ & 22 \\
Epinephelus lanceolatus & $19-70$ & $\mathrm{TL}_{\mathrm{PR}}=0.83 \mathrm{TL}_{\mathrm{CA}}-2.48(\mathrm{M})$ & Present study \\
E. coioides & $10-70$ & $\mathrm{TL}_{\mathrm{PR}}=0.80 \mathrm{TL}_{\mathrm{CA}}-1.50(\mathrm{M})$ & 14 \\
Lates calcarifer & $7-50$ & $\mathrm{TL}_{\mathrm{PR}}=0.59 \mathrm{TL}_{\mathrm{CA}}+0.07(\mathrm{M})$ & 23 \\
Seriola lalandi & $8-117$ & $\mathrm{TL}_{\mathrm{PR}}=0.54 \mathrm{TL}_{\mathrm{CA}}-2.45(\mathrm{O})$ & 19 \\
S. quinqueradiata & $\approx 6-38$ & $\mathrm{TL}_{\mathrm{PR}}=0.49 \mathrm{TL}_{\mathrm{CA}}+0.30(\mathrm{O})$ & 21 \\
Theragra chalcogramma & $51-174$ & $\mathrm{TL}_{\mathrm{PR}}=0.67 \mathrm{TL}_{\mathrm{CA}}-5.98(\mathrm{M})$ & 24
\end{tabular}

$\mathrm{TL}_{\mathrm{CA}}$ and $\mathrm{TL} \mathrm{L}_{\mathrm{PR}}$, total lengths of cannibal and prey; $\mathrm{M}$, equations derived from morphometric measurements; $\mathrm{O}$, equations derived from observed data.

ple, if prey TL is $30 \mathrm{~mm}$, based on equation 3 , a giant grouper cannibal with a TL larger than $39.13 \mathrm{~mm}$, in theory, can successfully ingest the conspecific prey. However, successful sea bass Lates calcarifer and striped amberjack Seriola lalandi cannibals need to exceed 50.72 and $60.10 \mathrm{~mm}$, respectively. A similar condition could be found in the orange-spotted grouper. Its slopes of MW and BD on TL are 0.20 and 0.25 , respectively. ${ }^{14}$ Therefore, we thought that the high relative growth rate of MW to BD (i.e. comparatively wider mouth and shallower body depth) is a generic character of the genus Epinephelus. This could make the grouper more particularly vulnerable to cannibalism than many other fishes.

To sum up, based on the morphometric study, we think that the giant grouper is comparatively more vulnerable to cannibalism during larviculture than many marine fishes, and suggest that 26$35 \%$ is a threshold in TL differences to use when grading giant grouper fry, at which point, potential cannibals should be removed. For fish like grouper with lower cannibal-to-prey sizes, Baras and Jobling suggested that the frequency of grading must be higher, and that grading must be applied over a longer time. ${ }^{5}$ We propose that grading will produce a much better effect in decreasing cannibalism when it is applied with other manipulations such as suitable feeding practices, optimal stocking densities, and supply of shelter, which have also been demonstrated to be effective in reducing fish cannibalism. ${ }^{10,11,15,18,20,26}$

\section{ACKNOWLEDGMENTS}

The authors thank Dr Shinn-Lih Yeh, Mr MingLong Chen, and Ms Hui-Fen Chang of the Fisheries Research Institute, Mariculture Research Center for their assistance in the study. This study was partially supported by the Council of Agriculture, Taiwan under grant no. 91AS-1.1.2.-FA-F1 (6) to Dr P. P. Hwang.

\section{REFERENCES}

1. Elgar MA, Crespi BJ. Ecology and evolution of cannibalism. In: Elgar MA, Crespi BJ (eds). Cannibalism: Ecology and Evolution Among Diverse Taxa. Oxford University Press, Oxford. 1992; 1-12.

2. Fox LR. Cannibalism in natural populations. Ann. Rev. Ecol. Syst. 1975; 6: 87-106.

3. Smith C, Reay P. Cannibalism in teleost fish. Rev. Fish Biol. Fish 1991; 1: 41-64.

4. Dominey J, Blumer LS. Cannibalism and early life stages of fishes. In: Hausfater G, Hardy SB (eds). Infanticide: Comparative and Evolutionary Perspectives. Aldine Publishing Co., New York. 1984; 43-64.

5. Baras E, Jobling M. Dynamics of intracohort cannibalism in cultured fish. Aquacult. Res. 2002; 33: 461-479.

6. Kubitza F, Lovshin LL. Formulated diets, feeding strategies, and cannibalism control during intensive culture of juvenile carnivorous fishes. Rev. Fish. Sci. 1999; 7: 1-22.

7. Heemstra PC, Randall JE. FAO species catalogue, Vol 16, Groupers of the World (Family Serranidae, Subfamily Epinephelinae). Food and Agriculture Organization of the United Nations, Rome. 1993.

8. Ho YS, Chen WY, Liao IC. Experiments on the artificial propagation of giant grouper Epinephelus lanceolatus. J. Taiwan Fish. Res. 1997; 5: 129-139 (in Chinese with English abstract).

9. Liao IC, Su HM, Chang EM. Techniques in finfish larviculture in Taiwan. Aquaculture 2001; 200: 1-31.

10. Fukuhara O. A review of the culture of grouper in Japan. Bull. Nansei Reg. Fish. Res. 1989; 22: 47-57.

11. Doi M, Munir MN, Nik Razali NL, Zulkifli T. Artificial propagation of the grouper, Epinephelus suillus at the Marine Finfish Hatchery in Tanjong Demong, Terengganu, Malaysia. Department of Fisheries, Ministry of Agriculture, Kuala Lumpur. 1991.

12. Lim LC. Larviculture of the greasy grouper Epinephelus tauvina $\mathrm{F}$ \& \& the brown-marbled grouper $E$, fuscoguttatus $\mathrm{F}$. in Singapore. J. World Aquacult. Soc. 1993; 24: 262-274.

13. Watanabe WO, Ellis SC, Ellis EP, Lopez VG, Bass P, Ginoza J, Moriwake A. Evaluation of first-feeding regimens for larval Nassau grouper Epinephelus striatus and preliminary politscale culture through metamorphosis. J. World Aquacult. Soc. 1996; 27: 324-331.

14. Hseu JR, Chang HF, Ting YY. Morphometric prediction of cannibalism in larviculture of orange-spotted grouper, Epinephelus coioides. Aquaculture 2003; 218: 203-207. 
15. Hseu JR. Effects of size difference and stocking density on cannibalism rate of juvenile grouper, Epinephelus coioides. Fish. Sci. 2002; 68: 1384-1386.

16. Narisawa Y, Kohno H, Fujita K. Development of swimmingand feeding-related characters in the grouper, Epinephelus coioides, larvae. J. Tokyo Univ. Fish. 1997; 84: 75-92 (in Japanese).

17. Fukuhara O, Fushimi T. Fin differentiation and squamation of artificially reared grouper, Epinephelus akaara. Aquaculture 1988; 69: 379-386.

18. Bry C, Basset E, Rognon X, Bonamy F. Analysis of sibling cannibalism among pike, Esox lucius, juveniles reared under semi-natural conditions. Environ. Biol. Fish. 1992; 35: 75-84.

19. Ebisu R, Tachihara K. Mortality caused by cannibalism is seed production of gold striped amberjack Seriola lalandi. Bull. Nagasaki Pref. Inst. Fish. 1993; 19: 1-7 (in Japanese).

20. Qin J, Fast AW. Size and feed dependent cannibalism with juvenile snakehead Channa striatus. Aquaculture 1996; 144: 313-320.
21. Sakakura Y, Tsukamoto K. Onset and development of cannibalistic behaviour in early life stages of yellowtail. J. Fish Biol. 1996; 48: 16-29.

22. Brownell CL. Laboratory analysis of cannibalism by larvae of the cape anchovy Engraulis capensis. Trans. Am. Fish. Soc. 1985; 114: 512-518.

23. Parazo MM, Avila EM, Reyers DM Jr. Size- and weightdependent cannibalism in hatchery-bred sea bass (Lates calcarifer Bloch). J. Appl. Ichthyol. 1991; 7: 1-7.

24. Sogard SM, Olla BL. The potential for intracohort cannibalism in age-0 walleye pollock, Theragra chalcogramma, as determined under laboratory conditions. Environ. Biol. Fish. 1994; 39: 183-190.

25. Grover JJ. Trophic ecology of pelagic early-juvenile Nassau grouper, Epinephelus striatus, during an early phase of recruitment into demersal habitats. Bull. Mar. Sci. 1993; 33: 1117-1125.

26. Hecht T, Pienaar AG. A review of cannibalism and its implications in fish larviculture. J. World Aquacult. Soc. 1993; 24 : 246-261. 